\title{
The Effect of Ultrasonic Treatment on Water Absorption of Epoxy/Kenaf Core Fiber Composite
}

\author{
Mohd Hazizul Hamzah ${ }^{1}$, Nor Yuliana Yuhana ${ }^{* 1}$, Abu Bakar Sulong ${ }^{2}$

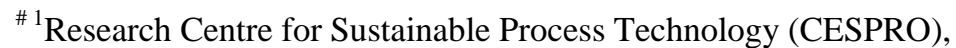 \\ Universiti Kebangsaan Malaysia, 43600 Bangi, Selangor, Malaysia. \\ ${ }^{1}$ hazizul_17@yahoo.com \\ *1yuliana@ukm.edu.my \\ ${ }^{2}$ Centre for Materials Engineering and Smart Manufacturing (MERCU), \\ Universiti Kebangsaan Malaysia, 43600 Bangi, Selangor Darul Ehsan. \\ 2abubakar@ukm.edu.my
}

\begin{abstract}
The effect of ultrasonic treatment on water absorbtion of epoxy/kenaf core fiber was studied. Kenaf core fiber was immersed in the $6 \%$ wt sodium hydroxide solution for 24 hours. Epoxy/kenaf core fiber then was mixed by using mechanical stirring, and then followed by ultrasonic mixing for $\mathbf{3 0}$ minutes, 60 minutes and 90 minutes before curing process. The cured samples were weighed before and after immersing them in distilled water, sea water and rain water at ambient temperature. The weight of the sample was taken twice per week for 28 days. Epoxy/kenaf core fiber that was treated with ultrasonic for 90 minutes has the lowest water uptake while untreated epoxy/kenaf core fiber has the highest water uptake. The introduction of ultrasonic treatment has helped to reduce water uptake for epoxy/kenaf core fiber composite. Most samples absorbed distilled water the most.
\end{abstract}

Keyword-Ultrasonic, Alkaline treatment, Water absorption, Epoxy, Kenaf core fiber

\section{INTRODUCTION}

Epoxy is a polymer widely used for coating mainly in electronic and civil works. As a coating agent, epoxy must have some resistant to heat, water and crack. However, they are brittle, low impact and fracture strengths and also show high moisture absorption [5].

Kenaf (Hibiscus cannabinus, L. family Malvacea) have been commercially used as industrial fibers in various industries such as in fiberboard, paper, mattresses, cushions, thermoplastic composites, insulator, wall panels, and doors [11]. It is widely study as a reinforcement material for composites because of its excellent properties and ecological consideration; it is easily grow and plant, and composed of many useful components [4]. Kenaf has branchless stem which consist of two layers; outer layer which is bastfiber and inner layer which is core [2]. Water absorption of composite will increase with the increasing of kenaf core fiber [3], [9]. Increasing water absorption will resulted in decreasing of mechanical properties [6]. The increasing filler will increase the thermal stability of composites [9]. Treatment on kenaffiber helped reduced the weight loss of composite during heat exposure [13].

Chemical treatment modified the hydrogen bond of cellulose and improves the ability of polymer-cellulose bonding thus increase mechanical properties and reduce water uptake of the composite. Among all of the chemical treatment used, alkaline and silane treatments have been widely reported [10]. The alkalization treatment has improved the tensile properties of the short kenaf significantly as compared to untreated short kenaffiber [7]. 6\% of sodium hydroxide concentration was optimum concentration for kenaffiber treatment [2], [7].

Among all of the physical treatment available, ultrasound treatment energy is noteworthy, because ultrasound causes cavitation, which is generally considered as a significant post-indicator of modifying fibers surface [1]. Alkaline treatment remove impurity from fiber surface which help improve fiber/matrix adhesion and ultrasonic treatment separates fibril and allows extra $\mathrm{OH}$ groups that are essential for further improving the adhesion of polymer/fiber [1].

Cellulose particle size reduces into shorter fiber after being treated with ultrasound [12]. However, the highest reduction of particle size and crystallite size to the cellulose occurred within the first hour of ultrasonication, after which the efficiency of the ultrasonication decreased [12]. 
One hour ultrasonic treatment has higher glass transition temperature compared to three hour treatment [8]. Extra bubble form after three hour of sonication may cause bad adhesion between clay and epoxy matrix [8].

Kenaf core fiber was reported to achieve optimum result at 10\% weight [3], [9]. Highest tensile strength and lowest water uptake was reported by them in $10 \%$ weight percentage of kenaf core fiber compared to other.

This study is conducted with the aim to determine the effect of ultrasonic treatment on kenaf core fiber. Kenaf core fiber as stated before has a very high water uptake; it is easy to absorb water even at room temperature in the normal condition. With the help of modification of cellulose; this study will determine whether the kenaf core fiber will improve the epoxy resins or not.

\section{EXPERIMENTAL}

\section{A. Materials}

Kenaf core fiber (KCF) around 20 mesh sizes was obtained from Material Manufacturing Laboratory, Mechanical Engineering and Material Department, National University of Malaysia. Epoxy (EpikoteTM Resin 828) with curing agent (Baxxodur EC 301) bought from ASACHEM (M) Sdn. Bhd, Kajang, Selangor. Sea water was taken from Port Dickson, Negeri Sembilan.

\section{B. Sample preparation}

Kenaf core fiber was weighted and dried in the oven at $105{ }^{\circ} \mathrm{C}$ for 24 hours. Sodium hydroxide $6 \%$ solution was prepared then by dissolving 6 gram of $99.99 \%$ solid sodium hydroxide into 100 gram of distilled water. Kenaf core fiber was immersed into the $6 \%$ sodium hydroxide solution for 24 hours. Treated kenaf core fiber then was washed by distilled water to remove sodium hydroxide trace before dried again in the oven at $105{ }^{\circ} \mathrm{C}$ for the next 24 hours.

100 gram of Epoxy (EpikoteTM Resin 828) was heated until $55^{\circ} \mathrm{C}$ by using heater. 10 gram of kenaf core fiber was added inside the epoxy and stirred at $50 \mathrm{rpm}$ for one hour. Epoxy/kenaf core fiber then was treated by using ultrasonic bath for 30 minutes, 60 minutes and 90 minutes before adding 31.89 gram of curing agent (Baxxodur EC 301) into mixture and stirred for 10 minutes. The mixture is then poured into mould and left to harden at room temperature for one week.

There are six sample prepared in total to justified the test required. The weight and mixture was prepared as follow;

TABLE 1.Sample Preparation Table

\begin{tabular}{|c|c|c|c|c|}
\hline Sample No. & Epoxy (g) & $\begin{array}{l}\text { Kenaf Core } \\
\text { Fiber (g) }\end{array}$ & $\begin{array}{l}\text { Sodium Hydroxide } \\
\text { 6\% Treatment (h) }\end{array}$ & $\begin{array}{l}\text { Ultrasonic } \\
\text { Treatment (min) }\end{array}$ \\
\hline 1 & 100 & 0 & - & - \\
\hline 2 & 100 & 10 & - & - \\
\hline 3 & 100 & 10 & 24 & - \\
\hline 4 & 100 & 10 & 24 & 30 \\
\hline 5 & 100 & 10 & 24 & 60 \\
\hline 6 & 100 & 10 & 24 & 90 \\
\hline
\end{tabular}

\section{Water Absorption Test}

There are a few standards that can be followed for water absorption test. This study will follow ASTM D570 with slightly modified. The sample is cut into small pieces; $3 \mathrm{~cm} \times 3 \mathrm{~cm} \times 0.2 \mathrm{~cm}$ in dimension. The sample is weight and dipped in distilled water, sea water and rain water at ambient temperature. The weight of the sample was taken twice per week for 28 days.The percentage of water uptake is calculated as follow,

$$
W A(\%)=\left[\frac{M_{1}-M_{0}}{M_{0}}\right] \times 100
$$

where $\mathrm{M}_{0}$ and $\mathrm{M}_{1}$ were the dried weight and final weight of the sample respectively. 


\section{III.RESULT AND DISCUSSION}

\section{A. Distilled Water}

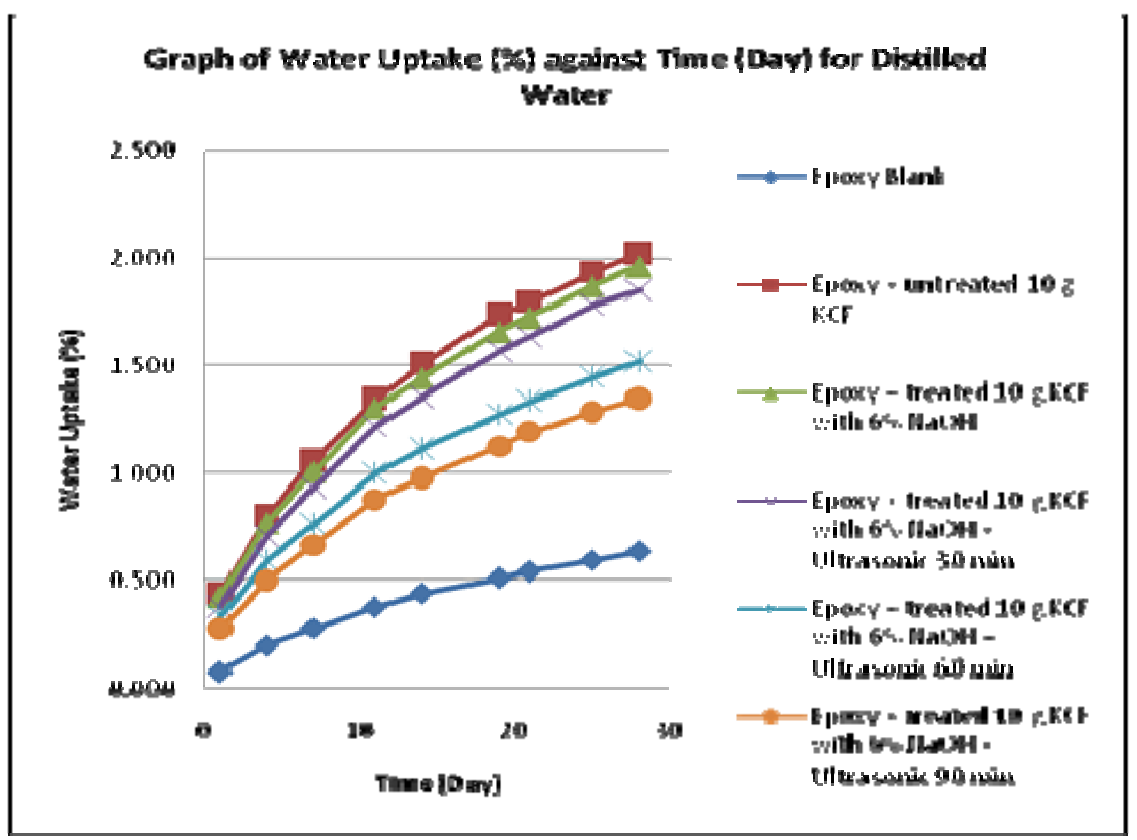

Fig. 1. Graph of water uptake, $\mathrm{M}_{\mathrm{t}}(\%)$ against time (day) for distilled water

Fig. 1 above shows the differences of water uptake level for each sample against time of immersion. Blank epoxy shows the lowest water uptake level compared to other sample. After reinforcing epoxy with various treated kenaf core fiber, epoxy reinforced with treated kenaf core fiber with 6\% sodium hydroxide and 90 minutes ultrasonic bath show the lowest possible water uptake at $1.349 \%$ after 28 days. This is because of the ultrasonic treatment help improve compatibility between fiber and polymer ${ }^{1}$. Untreated kenaf core fiber has the highest result of water uptake at $2.022 \%$ after 28 days.

B. Sea Water

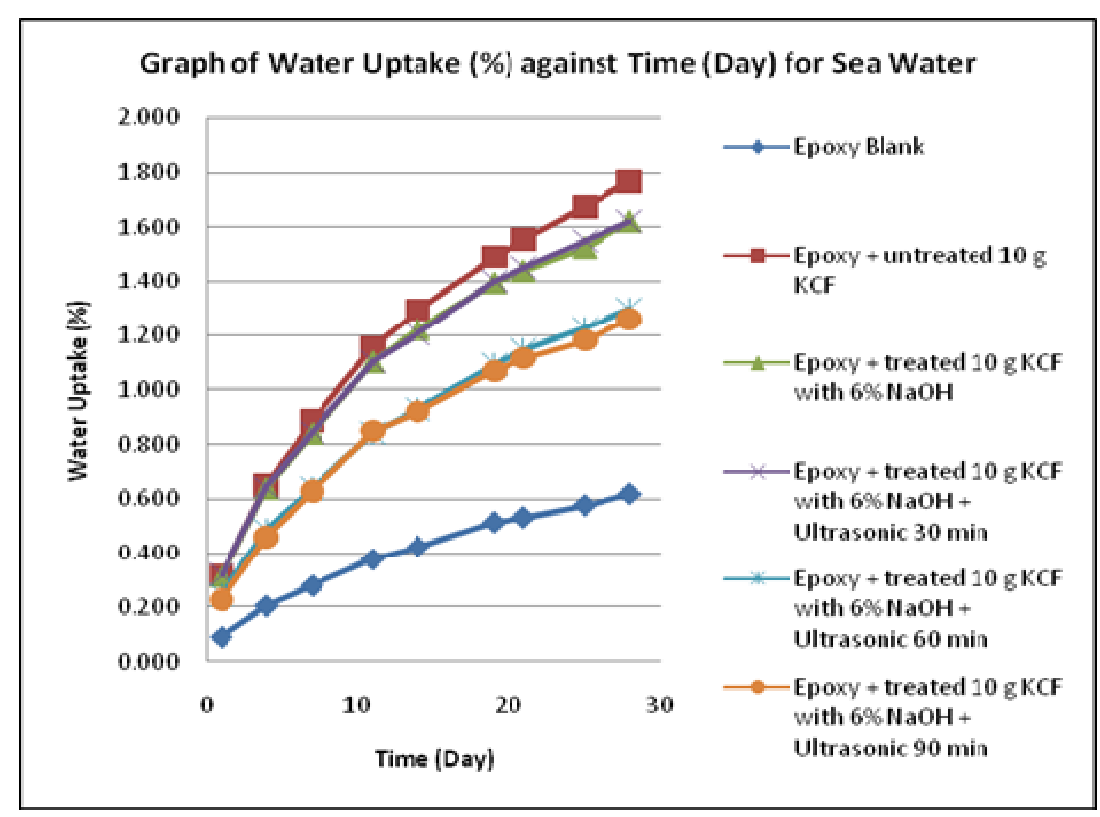

Fig. 2. Graph of water uptake, $\mathrm{M}_{\mathrm{t}}(\%)$ against time (day) for sea water

From fig. 2, the treated epoxy/kenaf core fiber with sodium hydroxide and ultrasonic in 90 minutes shows the lowest water uptake at $1.262 \%$ after 28 days compared to the other epoxy reinforced with kenaf core fiber. Untreated kenaf core fiber has the highest result of water uptake at $1.769 \%$ after 28 days. 


\section{Rain Water}

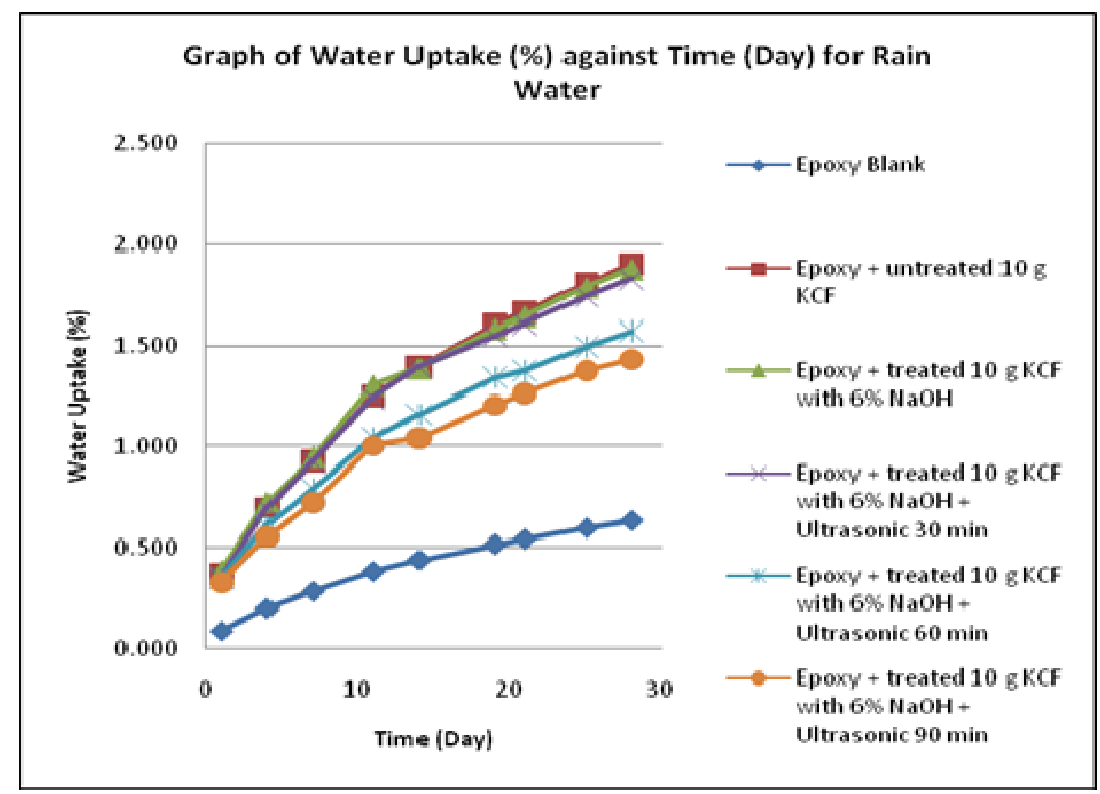

Fig. 3. Graph of water uptake, $M_{t}(\%)$ against time (day) for rain water

From fig. 3, the treated epoxy/kenaf core fiber with sodium hydroxide and ultrasonic in 90 minutes shows the lowest water uptake at $1.431 \%$ compared to the other epoxy reinforced with kenaf core fiber after 28 days. Untreated kenaf core fiber has the highest result of water uptake at $1.908 \%$ in this rain water immersion test.

D. Comparison Between Three Types of Water Immersion

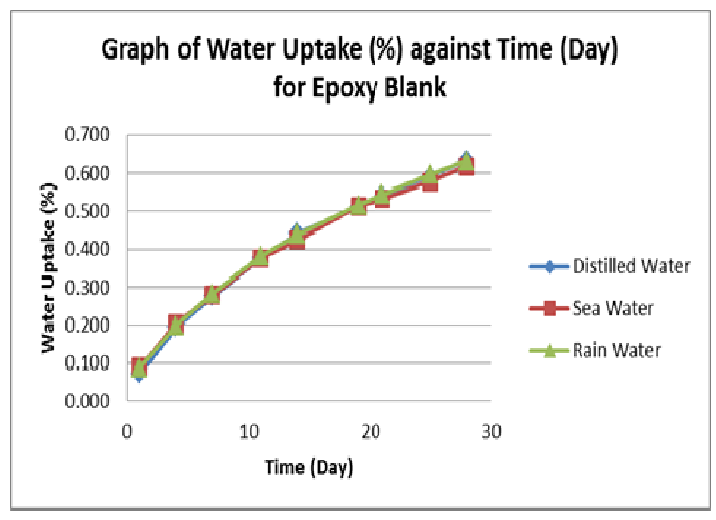

(a) Blank epoxy.

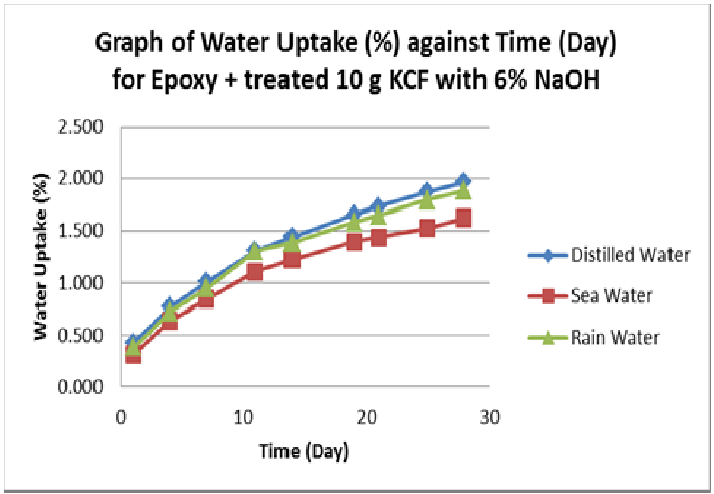

(c) Epoxy + treated KCF with 6\% $\mathrm{NaOH}$

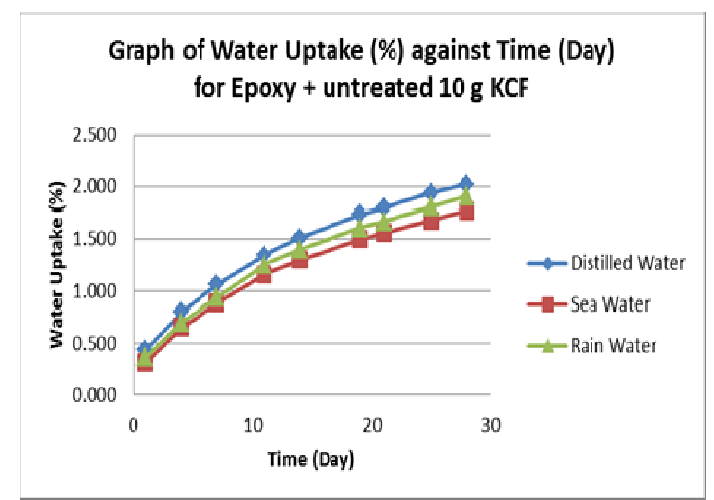

(b) Epoxy + untreated KCF.

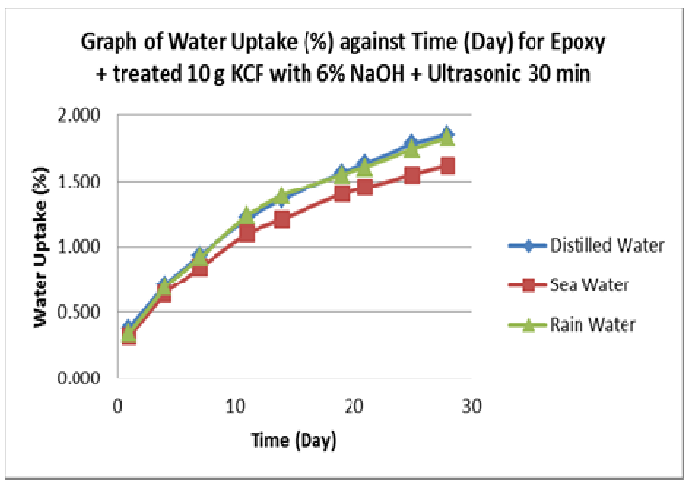

(d) Epoxy + treated KCF with 6\% $\mathrm{NaOH}+$ Ultrasonic 30 min 


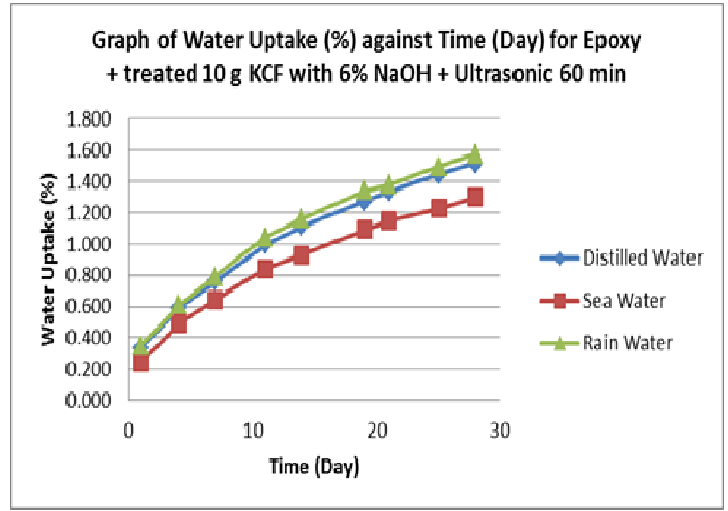

(e) Epoxy + treated KCF with 6\% $\mathrm{NaOH}+$ Ultrasonic $60 \mathrm{~min}$

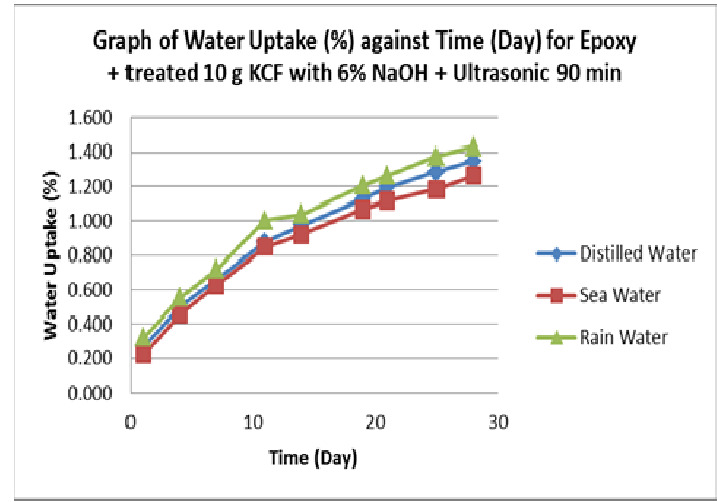

(f) Epoxy + treated KCF with 6\% NaOH + Ultrasonic 90 min

Fig. 4. Comparison for each water types in different sample condition

From the results, sea water shown to have the lowest water uptake compared to distilled water and rain water. This is because of sea water density and salinity [14]. Seedling that grown in saline soil shown reduction in water content and water potential of leaves, stems, tap roots and lateral roots [15]. This explained why pure blank epoxy shown no differences in all type of water uptake but after kenaf core fiber was added into epoxy, there is a huge difference of water uptake between distilled water/rain water and sea water. Salinity of sea water affected kenaf core fiber which is made of cellulose that reduce water uptake of epoxy/kenaf core fiber immersed in sea water.

\section{CONCLUSION}

Epoxy/kenaf core fiber was successfully prepared, treated and immersed in three different water; distilled water, rain water and sea water. Epoxy/kenaf core fiber that was treated with ultrasonic for 90 minutes has the lowest water uptake while untreated epoxy/kenaf core fiber has the highest water uptake. This is because of the ultrasonic treatment help improve compatibility between fiber and polymer thus making the sample slightly hydrophobic. The introduction of ultrasonic treatment has help reduce water uptake of epoxy/kenaf core fiber.

Epoxy/kenaf core fiber absorbs distilled water and rain water more than sea water. The increasing of water content in the sample is due to the formation of hydrogen bonding between water molecules and cellulose fiber. Each sample absorbs distilled water and rain water in almost equal amount to each other.

Most samples absorb distilled water the most. However, the sample that was treated in 60 minutes and 90 minutes ultrasonic shown to have absorb more of rain water than distilled water. Sea water remain as the lowest possible water uptake which is because of salinity of sea water affected kenaf core fiber which is made of cellulose that reduce water uptake of epoxy/kenaf core fiber immersed in sea water.

\section{ACKNOWLEDGMENT}

The authors wish to acknowledge Universiti Kebangsaan Malaysia for the supports through the GGPI-2016006 and GUP-2017-041 grants.

\section{REFERENCES}

[1] A.K.M. MoshiulAlam, M.D.H. Beg, D.M. Reddy Prasad, M.R. Khan and M.F. Mina, "Structures and performances of simultaneous ultrasound and alkali treated oil palm empty fruit bunch fiber reinforced poly(lactic acid) composites,” Composites Part A: Applied Science and Manufacturing, vol. 43, pp. 1921-1929, Nov. 2012.

[2] A.M. MohdEdeerozey, HazizanMdAkil, A.B. Azhar and M.I. Zainal Ariffin, “Chemical modification of kenaffibers,” Materials Letters, vol. 61, pp. 2023-2025, Apr. 2007.

[3] C.X. Viet, H. Ismail, A.A. Rashid and T. Takeichi, "Kenaf powder filled recycled high density polyethylene/natural rubber biocomposite: the effect of filler content,” International Journal of Integrated Engineering, vol. 4, pp. 22-25, Sep. 2012.

[4] H.M. Akil, M.F. Omar, A.A.M. Mazuki, S. Safiee, Z.A.M. Ishak and A. Abu Bakar, "Kenaffiber reinforced composites: a review," Materials \& Design, vol. 32, pp. 4107-4121, Sep. 2011.

[5] Hafsat R. Saliu, U.S. Ishiaku, M.K. Yakubu, E.G. Kolawole, S.S. Adefila, M.B. Abu Bakar and Z.A. Moh'dIshak, "The effect of epoxy concentration and fiber loading on the mechanical properties of ABS/Epoxy-Coated kenaffiber composites," Open Journal of Composite Material, vol. 5, pp. 41-48, Apr. 2015.

[6] M.A.A Ghani, Z. Salleh, Koay Mei Hyie, M.N. Berhan, Y.M.D. Taib and M.A.I. Bakri, "Mechanical properties of kenaf/fiberglass polyester hybrid composite,” Procedia Engineering, vol. 41, pp. 1654-1659, 2012.

[7] MohdSuhairilMeon, Muhamad Fauzi Othman, Hazran Husain, Muhammad Fairuz Remeli and MohdSyaharMohdSyawal, "Improving tensile strength of kenaf fibers treated with sodium hydroxide,” Procedia Engineering, vol. 41, pp. 1587-1592, 2012.

[8] N.Y. Yuhana, S. Ahmad and A.R. ShamsulBahri, "The Effect of Ultrasonic Treatment on Thermal Stability of the Cured Epoxy/Layered Silicate Nanocomposite,” Advances in Materials Science and Engineering, vol. 2012, pp. 1-5, Jan. 2012.

[9] NorshahidaSarifuddin, Hanafi Ismail and Zuraida Ahmad, "The effect of kenaf core fiber loading on properties of low density polyethylene/thermoplastic sago starch/kenaf core fiber composite,” Journal of Physical Science, vol. 24, pp. 97-115, 2013.

[10] O.M.L Asumani, R.G. Reid and R. Paskaramoorthy, "The effect of alkali-silane treatment on the tensile and flexural properties of short fiber non-woven kenaf reinforced polypropylene composites,” Composites Part A: Applied Science and manufacturing, vol. 43, pp. 1431-1440, Sep. 2012. 
[11] S. Misha, S. Mat, M.H. Ruslan, E. Salleh and K. Sopian, "Performance of a solar assisted solid desiccant dryer for kenaf core fiber drying under low solar radiation,” Solar Energy, vol. 112, pp. 194-204, Feb. 2015.

[12] SumariSumari, AchmadRoesyadi and SumarnoSumarno, "Effects of Ultrasound on the Morphology, Particle Size, Crystallinity, and Crystallite Size of Cellulose,” St. Cerc. St. CICBIA2013, vol. 14, pp. 229 - 239, Dec. 2013.

[13] Z.N. Azwa and B.F. Yousif, "Characteristics of kenaffiber/epoxy composites subjected to thermal degradation," Polymer Degradation and Stability, vol. 98, pp. 2752-2759, Dec. 2013.

[14] Amuthakkannan Pandian, ManikandanVairavan, WinowlinJappesJebbasThangaiah and MarimuthuUthayakumar, "Effect of moisture absorption behavior on mechanical properties of basalt fibre reinforced polymer matrix composites,” Journal of Composites, vol. 2014, pp. 1-8, Mar. 2014.

[15] Mamta J. Bhatt, Ashish D. Patel, Pranali M. Bhatti and Amar Nath Pandey, "Effect of soil salinity on growth, water status and nutrient accumulation in seedlings of ziziphusmauritiana (Rhamnaceae),” Journal of Fruit and Ornamental Plant Research, vol. 16, pp. 383-401, Jul. 2018. 